\title{
Endoscopic treatment of gastric antral vascular ectasia
}

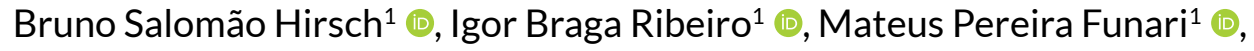 \\ Vitor Massaro Takamatsu Sagae ${ }^{1} \mathbb{D}$, Fabio Catache Mancini ${ }^{1} \mathbb{C}^{\circ}$, \\ Guilherme Henrique Peixoto de Oliveira ${ }^{1}$ (1), Eduardo Guimarães Hourneaux de Moura ${ }^{1}$ (D), \\ Wanderley Marques Bernardo ${ }^{1 *}$ (1)
}

The Guidelines Project, an initiative of the Brazilian Medical Association, aims to combine information from the medical field, to standardize how to conduct, and to assist in the reasoning and decision-making of doctors. The information provided by this project must be critically evaluated by the physician responsible for the conduct that will be adopted depending on the conditions and the clinical condition of each patient.

Guideline conclusion: April 2021.

Societies: Sociedade Brasileira de Endoscopia Digestiva.

\section{INTRODUCTION}

Gastric antral vascular ectasia (GAVE) is usually a condition characterized by vascular lesions located in the antrum, typically leading to occult or overt bleeding. It accounts for up to $4 \%$ of all nonvariceal upper gastrointestinal bleeding and may be present in 6-14\% of patients with cirrhosis ${ }^{1,2}$. Patients commonly present with chronic iron deficiency caused by anemia, and up to $62 \%$ of patients may become transfusion-dependent ${ }^{3}$.

Although the exact pathogenesis is still unclear, it has been proposed that abnormal gastric contraction waves induce prolapse of the antral mucosa with intermittent obstruction of blood vessels, resulting in fibromuscular hyperplasia. The imbalance of vasoactive and angiogenic mediators, such as prostaglandin E2, vasoactive intestinal peptide, 5-hydroxytryptamine, and gastrin, may also be involved in the pathogenesis ${ }^{4,5}$. Cirrhosis, connective tissue disorders, end-stage kidney disease, and bone marrow transplantation are disorders associated with GAVE development. Diagnosis is usually established by esophagogastroduodenoscopy; however, uncertain cases require histological assessment ${ }^{6,7}$. Endoscopically, it may present with three different patterns: stripes radiating to the pylorus (classically called "watermelon stomach," more common in noncirrhotic patients), diffuse punctate lesions (more common in cirrhotic patients), and a nodular type ${ }^{8,9}$. Histological features of GAVE include tortuous and dilated mucosal capillaries, often occluded by thrombi, and dilated submucosal veins surrounded by fibrohyalinosis and fibromuscular hyperplasia. The main differential diagnosis is portal hypertensive gastropathy (PHG).

Regarding treatment options, pharmacological therapies, such as beta-blockers, octreotide, thalidomide, or tranexamic acid, provide less benefits ${ }^{4,10-12}$. Antrectomy has higher morbidity and mortality. Transjugular intrahepatic portosystemic shunt is also not an effective therapy ${ }^{13}$. Therefore, the mainstay of treatment for GAVE is endoscopic therapy.

Argon plasma coagulation (APC) is a noncontact technique that delivers high-frequency monopolar current through ionized argon gas, resulting in tissue coagulation with limited depth of injury and lower risk of complications ${ }^{14,15}$. Endoscopic band ligation (EBL), first described as a treatment for esophageal varices, was further introduced as a treatment of GAVE. It consists of mechanical strangulation of the lesions by multiple elastic bands placement, resulting in thrombosis, necrosis, and subsequent fibrosis of the mucosa and submucosa ${ }^{16,17}$. Heater probe, Nd-YAG laser, sclerotherapy, and cryotherapy have been largely replaced due to complications of lower success rates and/or availability issues ${ }^{4}$. More recently, radiofrequency ablation (RFA) ${ }^{18,19}$ and hybrid-APC ${ }^{20}$ have emerged as alternative therapies.

Despite considerable recurrence rates, APC remains the most widely used endoscopic treatment for GAVE, although EBL shows promising results. Our aim was to perform a systematic review and meta-analysis in order to evaluate the best treatment option for this condition.

\footnotetext{
${ }^{1}$ Universidade de São Paulo, Hospital das Clínicas da Faculdade de Medicina da, Gastrointestinal Endoscopy Unit - São Paulo, Brazil.

*Corresponding author:wmbernardo@usp.br

Conflicts of interest: the authors declare there is no conflicts of interest. Funding: none.

Received on October 18, 2021. Accepted on October 18, 2021.
} 


\section{METHODS}

We performed a comprehensive search in electronic databases (i.e., MEDLINE, Embase, Cochrane, and LILACS) and grey literature. Only randomized controlled trials (RCTs) comparing APC and EBL for the treatment of GAVE were included.

A systematic review and meta-analysis were performed according to PRISMA guidelines using the PICO system. The risk of bias was assessed by the Cochrane risk-of-bias tool for randomized trials (RoB2). We analyzed the risk of bias for each outcome of every included study. The quality of evidence was assessed using the Grading of Recommendations Assessment, Development, and Evaluation (GRADE) criteria. The statistical analyses were conducted using the RevMan software, version 5.4, exposing the results as forest plots.

\section{RESULTS}

The search strategy identified 5,587 articles. After the removal of duplicates, 1,478 articles were screened. Among them, 11 were eligible for full-text review. Five observational studies, one review, and one study with duplicate data were excluded. Four $^{21-24}$ randomized clinical trials met the inclusion criteria, totaling 204 patients and comparing EBL with APC
(102 patients in each group) (Annex Figure 1). The baseline characteristics of the population and the results of individual studies are reported in Table 1. All included studies had a follow-up period of 6 months.

\section{Risk of bias and quality of studies}

The overall risk of bias is reported in Annex Table 1. We considered that the overall risk of bias was not serious. The quality of the included studies was considered adequate (Annex Table 2).

\section{Endoscopic eradication}

A total of 116 patients were analyzed from three studies ${ }^{21,23,24}$. EBL presented a higher endoscopic eradication rate compared with APC (risk difference [RD]: 0.29, 95\% confidence interval (CI): [0.14, 0.44], $\mathrm{p}=0.0001, \mathrm{I}^{2}=0 \%$ ) (Annex Figure 2). The GRADE analysis revealed a high certainty of evidence.

\section{Recurrence of bleeding}

A total of 116 patients were analyzed from three studies ${ }^{21,23,24}$. EBL presented a less recurrence of bleeding compared with the APC group (RD: 0.29, 95\%CI: [0.15, 0.44], p<0.0001, $\mathrm{I}^{2}=0 \%$ ) (Annex Figure 3). The GRADE analysis revealed a high certainty of evidence.

Table 1. Baseline characteristics of the population and the results of individual studies.

\begin{tabular}{|c|c|c|c|c|c|c|c|c|}
\hline & \multicolumn{2}{|c|}{ Abdelhalim (2014) } & \multicolumn{2}{|c|}{ Elhendawy (2015) } & \multicolumn{2}{|c|}{ Ghobrial (2018) } & \multicolumn{2}{|c|}{ Al-Wahab (2019) } \\
\hline & EBL & APC & EBL & APC & EBL & APC & EBL & APC \\
\hline No. of patients & 20 & 20 & 44 & 44 & 20 & 20 & 18 & 18 \\
\hline Mean age (years) & 55.65 & 57.17 & 51.41 & 53.09 & 9.65 & 7.8 & 65 & 60 \\
\hline Bleeding (occult/overt [\%]) & $20 / 80$ & $45 / 55$ & $\mathrm{NI}$ & $\mathrm{NI}$ & $0 / 100$ & $0 / 100$ & $17 / 83$ & $23 / 77$ \\
\hline Gender (male/female) & $9 / 11$ & $10 / 10$ & $19 / 25$ & $15 / 29$ & $13 / 7$ & $11 / 9$ & $11 / 7$ & $15 / 3$ \\
\hline APC settings & - & $\begin{array}{l}60 \mathrm{~W} \\
2 \mathrm{~L} / \mathrm{min}\end{array}$ & - & $\begin{array}{c}60 \mathrm{~W} \\
2 \mathrm{~L} / \mathrm{min}\end{array}$ & - & $\begin{array}{c}40 \mathrm{~W} \\
1 \mathrm{~L} / \mathrm{min}\end{array}$ & - & $\begin{array}{l}50 \mathrm{~W} \\
2 \mathrm{~L} / \mathrm{min}\end{array}$ \\
\hline No. of bands & $\begin{array}{l}\text { Up to } 18 \\
\text { bands }\end{array}$ & - & $\begin{array}{l}\text { Up to } 12 \\
\text { bands }\end{array}$ & - & $\begin{array}{l}\text { Up to } 6 \\
\text { bands }\end{array}$ & - & $\mathrm{NI}$ & - \\
\hline No. of sessions required & 2. $25 \pm 0.64$ & $5.5 \pm 3.76$ & $2.93 \pm 0.846$ & $3.48 \pm 0.902$ & $1.85 \pm 0.18$ & $4.15 \pm 1.22$ & $2.25 \pm 0.38$ & $2.5 \pm 0.57$ \\
\hline Procedure time (min) & $\mathrm{NI}$ & $\mathrm{NI}$ & $\mathrm{NI}$ & $\mathrm{NI}$ & $9.4 \pm 1.21$ & $15.37 \pm 1.56$ & $\mathrm{NI}$ & $\mathrm{NI}$ \\
\hline Recurrence of bleeding & $1 / 20$ & $7 / 20$ & $\mathrm{NI}$ & $\mathrm{NI}$ & $1 / 20$ & $7 / 20$ & $3 / 18$ & $8 / 18$ \\
\hline Endoscopic eradication & $19 / 20$ & $12 / 20$ & $\mathrm{NI}$ & $\mathrm{NI}$ & $19 / 20$ & $12 / 20$ & $13 / 18$ & $10 / 18$ \\
\hline Hb level after intervention & $9.68 \pm 1.31$ & $8.92 \pm 2.12$ & $10.31 \pm 1.01$ & $9.85 \pm 0.906$ & $9.2 \pm 0.84$ & $9.02 \pm 1.32$ & $8.8 \pm 1$ & $8.7 \pm 0.9$ \\
\hline Mean no. of hospitalizations & $0.05 \pm 0.22$ & $0.5 \pm 0.95$ & $\mathrm{NI}$ & $\mathrm{NI}$ & $0.67 \pm 0.15$ & $0.95 \pm 0.18$ & $\mathrm{NI}$ & $\mathrm{NI}$ \\
\hline Transfusion requirements (units) & $0.15 \pm 0.67$ & $2.00 \pm 2.97$ & $2.5 \pm 0.70$ & $4.6 \pm 0.89$ & $0.44 \pm 0.1$ & $1.0 \pm 0.67$ & $\mathrm{NI}$ & $\mathrm{NI}$ \\
\hline $\begin{array}{l}\text { Transfusion requirements } \\
\text { (no. of patients, \%) }\end{array}$ & $\mathrm{NI}$ & $\mathrm{NI}$ & $2(4.5)$ & $5(11.4)$ & $\mathrm{NI}$ & $\mathrm{NI}$ & $3(17)$ & $7(39)$ \\
\hline Adverse events (no. of patients, \%) & $0 / 20(0)$ & $0 / 20(0)$ & $6 / 44(13)$ & $9 / 44(20)$ & $14 / 20(70)$ & $2 / 20(10)$ & 6/18 (33) & 0/18 (0) \\
\hline
\end{tabular}

NI: not informed; W: watts; L: liters. 


\section{Transfusion requirement}

A total of 116 patients were analyzed from three studies ${ }^{21-23}$. The EBL group required fewer transfusions (mean difference [MD]: 1.49, 95\%CI: [0.28, 2.71], $\mathrm{p}=0.02, \mathrm{I}^{2}=96 \%$ ) (Annex Figure 4). The GRADE analysis revealed a very low certainty of evidence.

\section{Number of sessions}

A total of 204 patients were analyzed from four studies ${ }^{21-24}$. The number of sessions required for complete obliteration of the lesions was higher in the APC group (MD: 1.38, 95\%CI: $[0.35,2.42], p=0.009, I^{2}=94 \%$ ) (Annex Figure 5). The GRADE analysis revealed a very low certainty of evidence.

\section{Mean number of hospitalizations}

A total of 80 patients were analyzed from two studies ${ }^{21,23}$. The EBL group required fewer hospitalizations than patients in the CPA group (MD: 0.29, 95\%CI [0.19, 0.39], $\mathrm{p}<0.00001$, $\mathrm{I}^{2}=0 \%$ ) (Annex Figure 6). The GRADE analysis revealed a moderate quality of evidence.

\section{Adverse events}

A total of 204 patients were analyzed from four studies ${ }^{21-24}$. There was no difference between the two techniques (RD: -0.20 , 95\%CI: [-0.48, 0.07], $\mathrm{p}=0.15, \mathrm{I}^{2}=91 \%$ ) (Annex Figure 7). The GRADE analysis revealed a very low certainty of evidence.

\section{DISCUSSION}

Gastric antral vascular ectasia is a common entity that can be present in both patients with and without cirrhosis and that has a different spectrum of treatment and behavior than PHG. It carries significant morbidity and financial impact when patients are often hospitalized, requiring endoscopic procedures and blood transfusions. Nonetheless, few high-quality studies have evaluated the most optimal treatment modality. We performed the first systematic review and meta-analysis, including only RCTs and evaluating both APC and EBL in the treatment of this entity (level of evidence 1A).

This meta-analysis demonstrated that EBL has higher rates of endoscopic eradication, a less recurrence of bleeding, and a reduction in transfusion requirements. These results may be explained because EBL acts in deeper gastric wall layers, leading to thrombosis and ischemia of the mucosa and submucosa, which are subsequently replaced by fibrous tissue (Figure 1). Consequently, blood flow in the feeding vessels of GAVE is interrupted and then GAVE is eradicated. In contrast, APC acts only on the mucosa. Since GAVE is characterized by dilation of the mucosal and submucosal vessels with focal thrombosis, it is understandable that the deeper action of EBL will promote less recurrence of these lesions.

Regarding the number of hospitalizations, we included the meta-analysis data from two studies, reporting a significant reduction in the mean number of hospitalizations per patient in the EBL group. Concerning safety, only a few adverse events

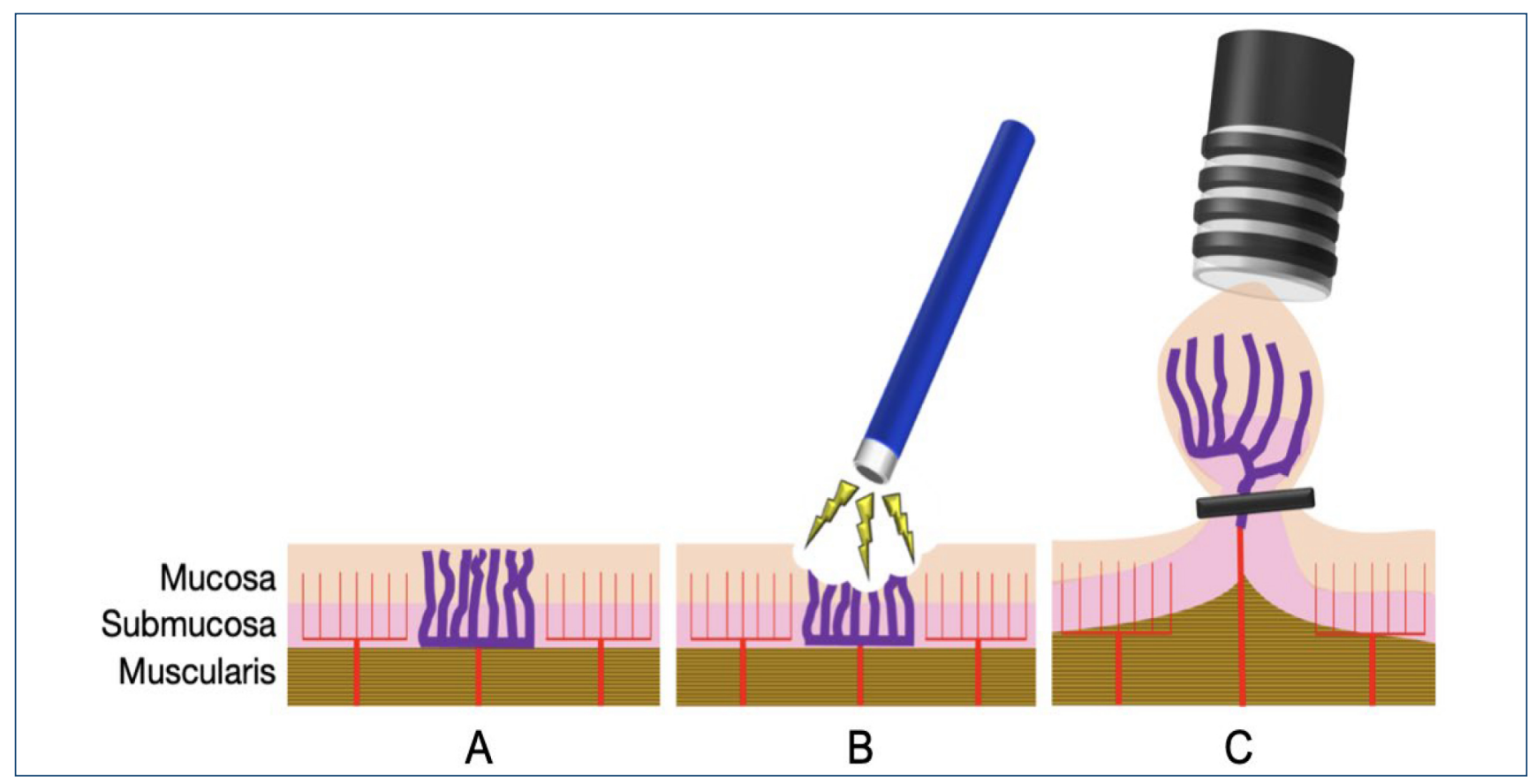

Figure 1. A: Mucosa with gastric antral vascular ectasia. B: Treatment with argon plasma coagulation. C: Treatment with endoscopic band ligation. 
were reported, such as fever, epigastric pain, abdominal distension, mild bleeding, and vomiting, with no difference within the procedures. No serious adverse events were observed, proving the safety of both methods according to the recommendations of the American Society for Gastrointestinal Endoscopy Quality Task Force ${ }^{25}$. One of the included studies ${ }^{24}$ reported the development of hyperplastic polyps in some patients undergoing EBL. However, an uncommon complication has been reported with APC and $\mathrm{RFA}^{26,27}$.

Despite the efficiency of both techniques to treat GAVE, EBL still has more advantages. It is more widely available and less time-consuming, and since it requires fewer endoscopic sessions, it is probably associated with reduced costs. However, in some situations, both techniques can be performed complementarily, especially in fibrotic areas related to the previous banding that are difficult to suction and to achieve band deployment.

The exposed results are consistent in patients with chronic liver disease, which represent the etiology of a considerable amount of the GAVE cases encountered in daily practice. However, other conditions associated with GAVE, such as connective tissue disorders, end-stage renal disease, and bone marrow transplantation, were not evaluated in this study? Since the pathogenesis is not fully understood, it is not possible to affirm that our results may be extrapolated to other diseases. Nevertheless, there are two retrospective studies, including patients with noncirrhotic GAVE and also reporting the superiority of EBL over APC.

In this study, we analyzed the two main endoscopic options (i.e., EBL and APC) for the treatment of GAVE. Promising emergent techniques, such as radiofrequency and hybrid-APC, have not been evaluated in RCTs and, therefore, not included in our study. More studies are needed to compare APC and EBL techniques. The treatment of GAVE is also limited by an incomplete understanding of its pathogenesis. Hence, it is possible that a more accurate understanding of the pathophysiology can lead to a better management of this condition.

Our study has several limitations. Few articles were included in the analysis. However, this is a limitation due to the small number of RCT published on this subject. All the included studies were conducted in the same country (Egypt), which is ranked among countries having the highest death rates of cirrhosis ${ }^{30}$. Nonetheless, our results were consistent with previous observational studies that were conducted in other countries as well ${ }^{28,29,31}$. Not all outcomes were evaluated in every trial. Significant heterogeneity was identified among the studies, which might be explained by the following reasons: the severity of the liver disease varies among the studies and different APC settings alongside a variable number of endoscopic bands applied on each session. These aforementioned reasons might have influenced the outcomes. One of the included studies was performed in children with liver disease ${ }^{23}$. However, the results were consistent with the other studies, probably due to the same pathophysiology in patients with chronic liver disease. Regarding the transfusion requirements, none of the studies informed the cutoff value to indicate blood transfusions. Nevertheless, all individual studies consistently reported fewer transfusions in patients with EBL.

\section{CONCLUSIONS}

We performed an extensive systematic and in-depth critical evaluation of the best level of evidence on this subject. The available data recommended EBL as the first option for the treatment of GAVE. We strongly believe that this can significantly and positively impact the care and management of patients suffering from this condition.

\section{Summary of recommendations}

EBL and APC are effective and safe procedures for the endoscopic treatment of GAVE. EBL is superior to APC in terms of endoscopic eradication rates, recurrence of bleeding, and need for transfusion. In some situations, both techniques can be performed in a complementary way. Both interventions had similar adverse events.

The level of evidence varies from high to very low, depending on the outcome analyzed.

\section{AUTHORS' CONTRIBUTIONS}

BSH, IBR, EGHM: Conceptualization. BSH: Data curation. BSH, IBR, MPF, VMS, FCM, GHPO, WMB, EGHM: Formal Analysis. BSH, WBM, EGHM: Methodology. BSH, WBM: Investigation, Project administration, Software. WBM, EGHM: Resources, Supervision, Validation. BSH, IBR, WBM, EGHM: Visualization. BSH, IBR, MPF, VMS, EGHM: Writing - original draft. BSH, IBR, MPF, VMS, FCM, GHPO, EGHM: Writing - review \& editing. 


\section{REFERENCES}

1. Dulai GS, Jensen DM, Kovacs TOG, Gralnek IM, Jutabha R. Endoscopic treatment outcomes in watermelon stomach patients with and without portal hypertension. Endoscopy. 2004;36(1):6872. https://doi.org/10.1055/s-2004-814112

2. Sebastian S, McLoughlin R, Qasim A, O'Morain CA, Buckley MJ. Endoscopic argon plasma coagulation for the treatment of gastric antral vascular ectasia (watermelon stomach): long-term results. Dig Liver Dis. 2004;36(3):212-7.https://doi.org/10.1016/j.dld.2003.11.028

3. Gretz JE, Achem SR. The watermelon stomach: clinical presentation, diagnosis, and treatment. Am J Gastroenterol. 1998;93(6):890-5. https://doi.org/10.1111/j.1572-0241.1998.00271.x

4. Fuccio L, Mussetto A, Laterza L, Eusebi LH, Bazzoli F. Diagnosis and management of gastric antral vascular ectasia. World J Gastrointest Endosc. 2013;5(1):6-13. https://doi.org/10.4253/wjge.v5.i1.6

5. Burak KW, Lee SS, Beck PL. Portal hypertensive gastropathy and gastric antral vascular ectasia (GAVE) syndrome. Gut. 2001;49(6):866-72. https://doi.org/10.1136/gut.49.6.866

6. Ripoll C, Garcia-Tsao G. Management of gastropathy and gastric vascular ectasia in portal hypertension. Clin Liver Dis. 2010;14(2):281-95. https://doi.org/10.1016/j.cld.2010.03.013

7. HsuW-H,Wang Y-K,HsiehM-S,KuoF-C,WuM-C,ShihH-Y,etal.Insights into the management of gastric antral vascular ectasia (watermelon stomach). Ther Adv Gastroenterol. 2018;11:1756283X17747471. https://doi.org/10.1177/1756283X17747471

8. Ito M,UchidaY, KamanoS, KawabataH, NishiokaM. Clinical comparisons between two subsets of gastric antral vascular ectasia. Gastrointest Endosc. 2001:53(7):764-70.https://doi.org/10.1067/mge.2001.113922

9. Thomas A, Koch D, Marsteller W, Lewin D, Reuben A. An analysis of the clinical, laboratory, and histological features of striped, punctate, and nodular gastric antral vascular ectasia. Dig Dis Sci. 2018;63(4):966-73. https://doi.org/10.1007/s10620-018-4965-z

10. Swanson E, Mahgoub A, MacDonald R, Shaukat A. Medical and endoscopic therapies for angiodysplasia and gastric antral vascular ectasia: a systematic review. Clin Gastroenterol Hepatol. 2014;12(4):571-82. https://doi.org/10.1016/j.cgh.2013.08.038

11. ASGE technology committee, Parsi MA, Schulman AR, Aslanian HR, Bhutani MS, Krishnan K, et al. Devices for endoscopic hemostasis of nonvariceal GI bleeding (with videos). VideoGIE. 2019;4(7):28599. https://doi.org/10.1016/j.vgie.2019.02.004

12. Selinger CP, Ang YS. Gastric antral vascular ectasia (GAVE): an update on clinical presentation, pathophysiology and treatment. Digestion. 2008;77(2):131-7.https://doi.org/10.1159/000124339

13. Kamath PS, Lacerda M, Ahlquist DA, McKusick MA, Andrews JC, Nagorney DA. Gastric mucosal responses to intrahepatic portosystemic shunting in patients with cirrhosis. Gastroenterology.2000;118(5):90511. https://doi.org/10.1016/s0016-5085(00)70176-4

14. Boltin D, Gingold-Belfer R, Lichtenstein L, Levi Z, Niv Y. Longterm treatment outcome of patients with gastric vascular ectasia treated with argon plasma coagulation. Eur J Gastroenterol Hepatol. 2014;26(6):588-93. https://doi.org/10.1097/ MEG.0000000000000047

15. Chaves DM, Sakai P, Oliveira CV, Cheng S, Ishioka S. Watermelon stomach: clinical aspects and treatment with argon plasma coagulation. Arq Gastroenterol. 2006;43(3):191-5. https://doi. org/10.1590/s0004-28032006000300007

16. Zepeda-Gómez S, Sultanian R, Teshima C, Sandha G, Zanten SV, Montano-Loza AJ. Gastric antral vascular ectasia: a prospective study of treatment with endoscopic band ligation. Endoscopy. 2015;47(6):538-40. https://doi.org/10.1055/s-0034-1391395

17. Eccles J, Falk V, Montano-Loza AJ, Zepeda-Gómez S. Long-term follow-up in patients with gastric antral vascular ectasia (GAVE) after treatment with endoscopic band ligation (EBL). Endosc Int Open. 2019;7(12):E1624-9.https://doi.org/10.1055/a-0977-2870

18. Gross SA,Al-HaddadM, Gill KRS, SchoreAN, Wallace MB. Endoscopic mucosal ablation for the treatment of gastric antral vascular ectasia with the HALO90 system: a pilot study. Gastrointest Endosc. 2008;67(2):324-7. https://doi.org/10.1016/j.gie.2007.09.020

19. Dray X, Repici A, Gonzalez P, Fristrup C, Lecleire S, Kantsevoy S, et al. Radiofrequency ablation for the treatment of gastric antral vascular ectasia. Endoscopy. 2014;46(11):963-9. https://doi. org/10.1055/s-0034-1377695

20. Hernández Mondragón OV, Lopez Valenzuela LA, Blancas Valencia JM, Espinosa Saavedra D, Blanco Velasco G. Safety and efficacy of hybrid-apc for the treatment of refractory gave. Endoscopy. 2018;50(4):S122. https://doi.org/10.1055/s-0038-1637393

21. Abdelhalim H,Mostafa I,Abdelbary MS, Elansary M,Abdo M, Rahim AA. Endoscopic band ligation versus argon plasma coagulation for the treatment of gastric antral vascular ectasia in Egyptian patients with liver cirrhosis. World J Med Sci. 2014;10(3):357-61.

22. Elhendawy M, Mosaad S, Alkhalawany W, Abo-Ali L, Enaba M, Elsaka A, et al. Randomized controlled study of endoscopic band ligation and argon plasma coagulation in the treatment of gastric antral and fundal vascular ectasia. United Eur Gastroenterol J. 2016;4(3):423-8. https://doi.org/10.1177/2050640615619837

23. Ghobrial C, Rabea M, Mohsen N, Eskander A. Gastric antral vascular ectasia in portal hypertensive children: endoscopic band ligation versus argon plasma coagulation. J Pediatr Surg. 2019;54(8):1691-5. https://doi.org/10.1016/j.jpedsurg.2018.07.015

24. Amer K, El-Wahab NA, Ibrahim A. Comparison between argon plasma coagulation and endoscopic band ligation in treatment of gastric antral vascular ectasia in Egyptian cirrhotic patients. Afro-Egypt J Infect Enem Dis. 2019;9(2):176-84. https://doi. org/10.21608/aeji.2019.12560.1024

25. Cotton PB, Eisen GM, Aabakken L, Baron TH, Hutter MM, Jacobson BC, et al. A lexicon for endoscopic adverse events: report of an ASGE workshop. Gastrointest Endosc. 2010;71(3):446-54.https:// doi.org/10.1016/j.gie.2009.10.027

26. Farooq FT, Wong RCK, Yang P, Post AB. Gastric outlet obstruction as a complication of argon plasma coagulation for watermelon stomach. Gastrointest Endosc. 2007;65(7):1090-2. https://doi. org/10.1016/j.gie.2006.10.006

27. Izquierdo S, Rey E, Gutiérrez Del Olmo A, Almansa C, Andrés Ramírez Armengol J, Díaz-Rubio M. Polyp as a complication of argon plasma coagulation in watermelon stomach. Endoscopy. 2005;37(9):921. https://doi.org/10.1055/s-2005-870332

28. Wells CD, Harrison ME, Gurudu SR, Crowell MD, Byrne TJ, Depetris G, et al. Treatment of gastric antral vascular ectasia (watermelon stomach) with endoscopic band ligation. Gastrointest Endosc. 2008;68(2):231-6. https://doi. org/10.1016/j.gie.2008.02.021

29. Keohane J, Berro W. Harewood GC, Murray FE, Patchett SE. Band ligation of gastric antral vascular ectasia is a safe and effective endoscopic treatment. Dig Endosc. 2013;25(4):392-6. https:// doi.org/10.1111/j.1443-1661.2012.01410.x

30. GBD 2017 Cirrhosis Collaborators. The global, regional, and national burden of cirrhosis by cause in 195 countries and territories, 1990-2017: a systematic analysis for the Global Burden of Disease Study 2017. Lancet Gastroenterol Hepatol. 2020;5(3):245-66 https://doi.org/10.1016/S2468-1253(19)30349-8

31. Sato T, Yamazaki K, Akaike J. Endoscopic band ligation versus argon plasma coagulation for gastric antral vascular ectasia associated with liver diseases. Dig. Endosc. 2012;24(4):237-42. https://doi. org/10.1111/j.1443-1661.2011.01221.x 


\section{ANNEX}

\section{METHODS}

\section{Protocol and Registration}

This study was performed in conformity with the Preferred Reporting Items for Systematic Reviews and Meta-Analyses guidelines, and it was registered in the International Prospective Register of Systematic Reviews under the file number CRD42020191896. This study was approved by the Ethics Committee of Hospital das Clínicas, Faculty of Medicine at The University of São Paulo.

\section{Eligibility criteria}

We screened all studies with the following inclusion criteria:

a. Study design: only RCTs.

b. Population: patients with GAVE, irrespective of age.

c. Type of intervention: argon plasma coagulation and EBL.

d. Outcomes: endoscopic eradication, recurrence of bleeding, blood transfusion requirements, number of sessions needed, number of hospitalizations, and adverse events.

\section{Search and Study Selection}

We performed a search in electronic databases (i.e., MEDLINE, Embase, Cochrane, and LILACS) and grey literature from their inception to March 2021. Only RCTs comparing APC and EBL for the treatment of GAVE were included. No restrictions were set for publication date or language. The search strategy in MEDLINE was gastric antral vascular ectasia OR antral vascular ectasia OR antral vascular ectasia OR watermelon stomach OR watermelon stomachs. In the other databases, the search was performed with the term "gastric antral vascular ectasia." Two independent investigators conducted the screening for eligibility. Any disagreements were resolved by consultation with a third reviewer.

\section{Data collection process}

The following data were extracted: name and year of the study, number of patients, age, gender, type of bleeding (i.e., occult or overt), argon plasma settings, number of bands, Child-Pugh score, number of sessions, procedure time, recurrence of bleeding, endoscopic eradication, hemoglobin level after the intervention, number of hospitalizations, transfusion requirements, and adverse events. When data of the published articles were insufficient, the corresponding authors were consulted by e-mail for further elucidation.

\section{Risk of bias and quality of studies}

The risk of bias was assessed by the RoB2. We analyzed the risk of bias for each outcome of every included study. The quality of the evidence was assessed using the GRADE criteria with the GRADEpro Guideline Development Tool software.

\section{Data synthesis and statistical analysis}

The sample mean was estimated, when needed, from its median and range ${ }^{(31)}$. The statistical analyses were conducted using the RevMan software, version 5.4. The Mantel-Haenszel test was used for categorical variables, and inverse variance was used for continuous variables. Heterogeneity was evaluated using the Higgins test $\left(\mathrm{I}^{2}\right)$. $\mathrm{I}^{2}$ values higher than $50 \%$ were considered substantial heterogeneity ${ }^{(30)}$. We used the fixed effect when $\mathrm{I}^{2}<50 \%$. If $\mathrm{I}^{2}>50 \%$, we performed a sensitivity analysis through a funnel plot to identify possible outliers. If the sample became homogeneous after the exclusion, the studies were permanently excluded (considered true outliers), and the fixed model was used. When there was no outlier or heterogeneity remained high after the outliers were excluded, we used the random effect to reduce the impact of heterogeneity on the final result. Outcome measures were described as mean difference or risk difference, with their corresponding 95\%CIs. Intention-to-treat analysis was performed in all studies. 


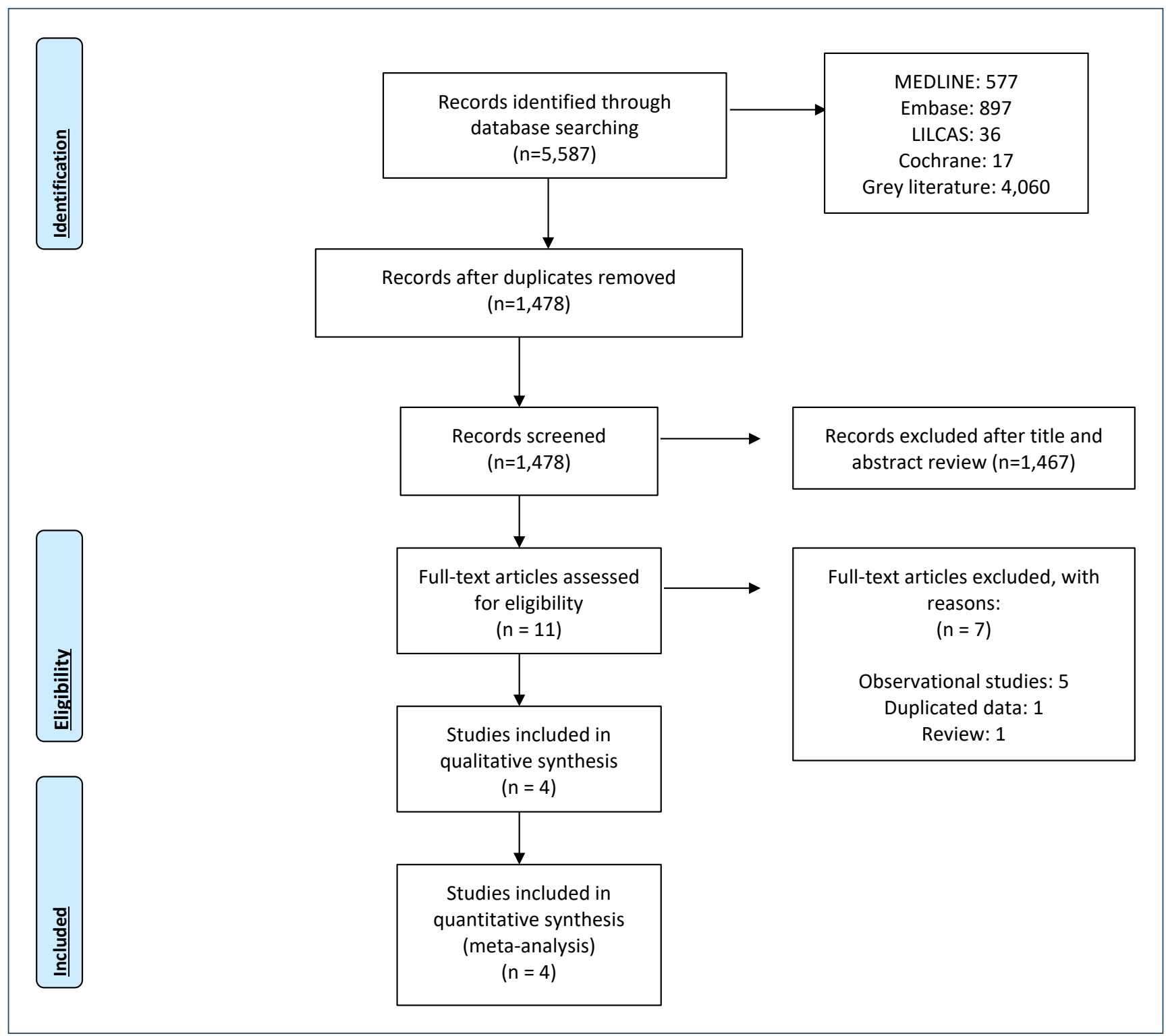

Annex Figure 1. PRISMA flow diagram.

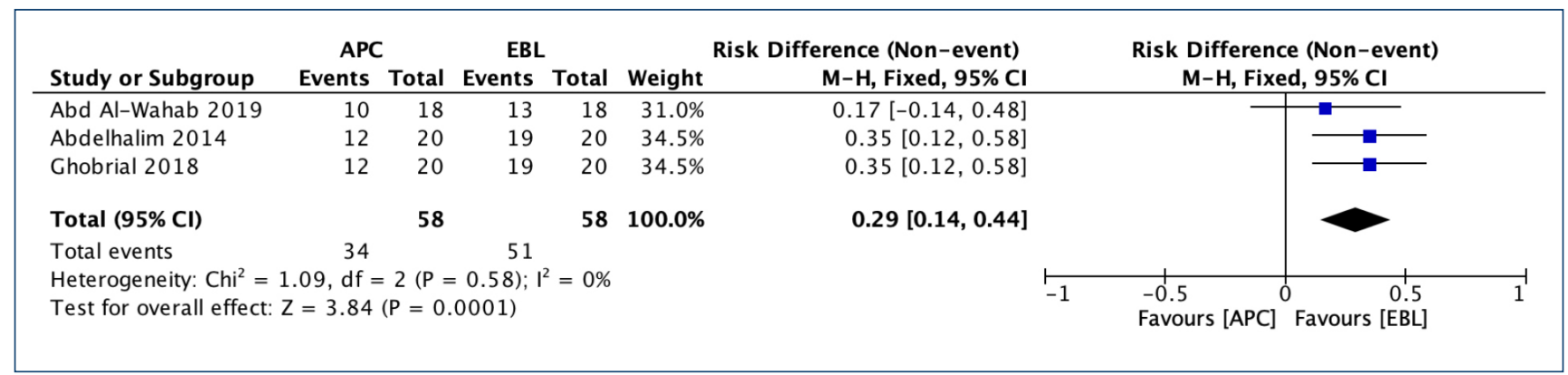

Annex Figure 2. Endoscopic eradication. 


\begin{tabular}{|c|c|c|c|c|c|c|c|c|c|}
\hline \multirow{2}{*}{$\begin{array}{l}\text { Study or Subgroup } \\
\text { Abd Al-Wahab } 2019\end{array}$} & \multirow{2}{*}{$\begin{array}{r}\begin{array}{r}\text { APC } \\
\text { Events }\end{array} \\
8\end{array}$} & \multirow{2}{*}{$\begin{array}{r}\text { Total } \\
18\end{array}$} & \multirow{2}{*}{$\begin{array}{r}\begin{array}{r}\text { EBI } \\
\text { Events }\end{array} \\
3\end{array}$} & \multirow{2}{*}{$\begin{array}{r}\text { Total } \\
18\end{array}$} & \multirow{2}{*}{$\begin{array}{r}\text { Weight } \\
31.0 \%\end{array}$} & $\begin{array}{l}\text { Risk Difference } \\
\text { M-H, Fixed, 95\% Cl }\end{array}$ & \multicolumn{2}{|c|}{$\begin{array}{c}\text { Risk Difference } \\
\text { M-H, Fixed, 95\% Cl }\end{array}$} & \\
\hline & & & & & & $0.28[-0.01,0.56]$ & & & \\
\hline Abdelhalim 2014 & 7 & 20 & 1 & 20 & $34.5 \%$ & $0.30[0.07,0.53]$ & & & \\
\hline Ghobrial 2018 & 7 & 20 & 1 & 20 & $34.5 \%$ & $0.30[0.07,0.53]$ & & & \\
\hline Total $(95 \% \mathrm{Cl})$ & & 58 & & 58 & $100.0 \%$ & $0.29[0.15,0.44]$ & & & \\
\hline Total events & 22 & & 5 & & & & & & \\
\hline $\begin{array}{l}\text { Heterogeneity: } \mathrm{Chi}^{2}= \\
\text { Test for overall effect }\end{array}$ & $\begin{array}{l}.02, d f= \\
z=4.01\end{array}$ & $\begin{array}{l}=2(P= \\
(P<0 .\end{array}$ & $\begin{array}{l}=0.99) ; 1 \\
.0001)\end{array}$ & $I^{2}=0 \%$ & & & $\begin{array}{l}-0.5 \quad 0 \\
\text { Favours [APC] }\end{array}$ & $\begin{array}{cr}0 & 0.5 \\
\text { Favours [EBL] }\end{array}$ & 1 \\
\hline
\end{tabular}

Annex Figure 3. Recurrence of bleeding.

\begin{tabular}{|c|c|c|c|c|c|c|c|c|c|c|c|c|}
\hline Study or Subgroup & \multicolumn{3}{|c|}{ APC } & \multicolumn{3}{|c|}{ EBL } & Weight & $\begin{array}{l}\text { Mean Difference } \\
\text { IV, Random, } 95 \% \mathrm{CI}\end{array}$ & \multicolumn{3}{|c|}{$\begin{array}{c}\text { Mean Difference } \\
\text { IV, Random, 95\% CI }\end{array}$} & \\
\hline Abdelhalim 2014 & 2 & 2.9 & 20 & 0.1 & 0.6 & 20 & $26.3 \%$ & $1.90[0.60,3.20]$ & & & ti- & \\
\hline Elhendawy 2016 & 4.6 & 0.8 & 44 & 2.5 & 0.7 & 44 & $36.8 \%$ & $2.10[1.79,2.41]$ & & & - & \\
\hline Ghobrial 2018 & 1 & 0.67 & 20 & 0.4 & 0.1 & 20 & $36.9 \%$ & $0.60[0.30,0.90]$ & & & - & \\
\hline Total $(95 \% \mathrm{Cl})$ & & & 84 & & & 84 & $100.0 \%$ & $1.49[0.28,2.71]$ & & & & \\
\hline $\begin{array}{l}\text { Heterogeneity: } \mathrm{Tau}^{2} \\
\text { Test for overall effect }\end{array}$ & $\begin{array}{l}1.01 \\
Z=2.4\end{array}$ & $\begin{array}{l}\mathrm{Chi}^{2}= \\
42(\mathrm{P}=\end{array}$ & $\begin{array}{l}47.05, \\
=0.02)\end{array}$ & $d f=$ & & 0.0000 & 1); $\left.\right|^{2}=96$ & & $\frac{1}{-4}$ & $\begin{array}{cc}1 & 1 \\
-2 & 0 \\
\text { Favours [APC] }\end{array}$ & $\begin{array}{r}1 \\
\text { Favours [EB }\end{array}$ & 4 \\
\hline
\end{tabular}

Annex Figure 4. Transfusion requirement.

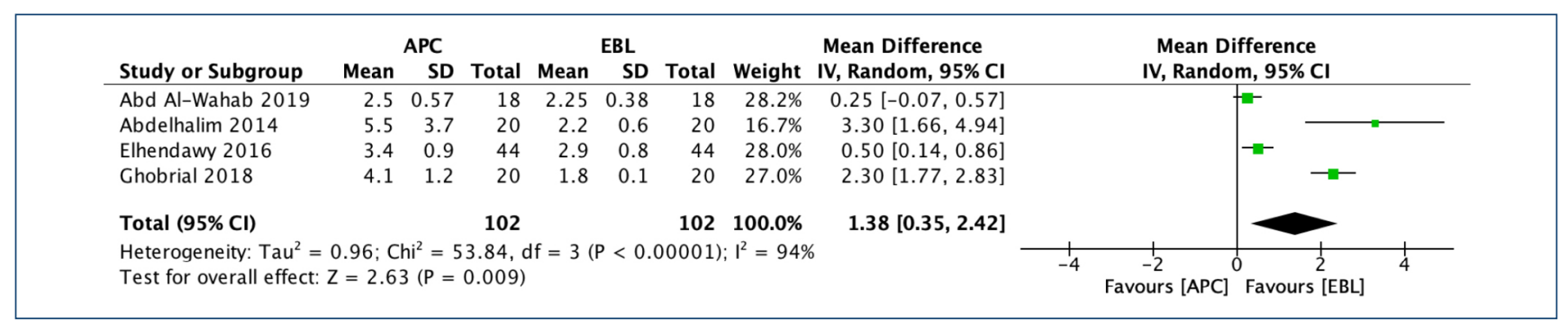

Annex Figure 5. Number of sessions.

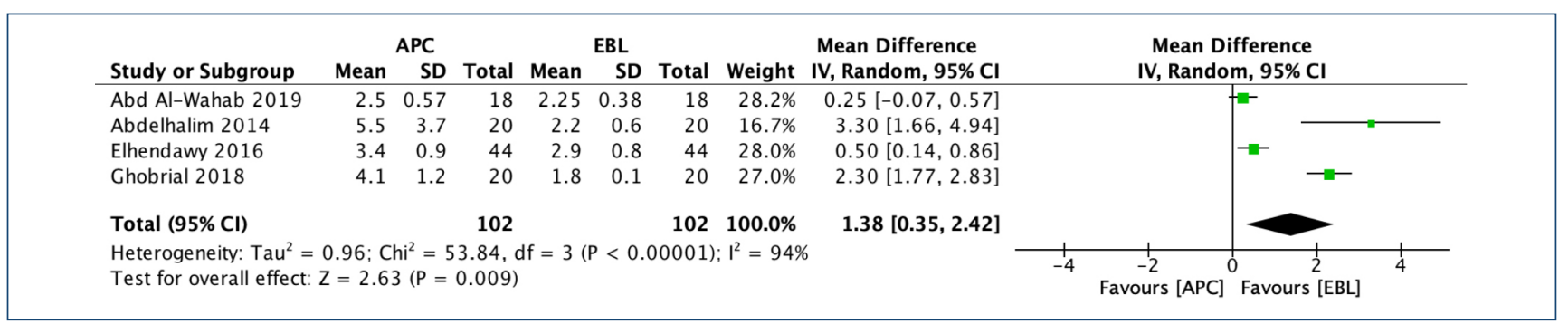

Annex Figure 6. Number of hospitalizations. 
Hirsch, B. S. et al.

\begin{tabular}{|c|c|c|c|c|c|c|c|c|}
\hline \multirow{2}{*}{$\begin{array}{l}\text { Study or Subgroup } \\
\text { Abd Al-Wahab } 2019\end{array}$} & \multirow{2}{*}{$\begin{array}{r}\text { APC } \\
\text { Events } \\
0\end{array}$} & \multirow{2}{*}{ Total } & \multirow{2}{*}{$\begin{array}{r}\text { EBL } \\
\text { Events } \\
6\end{array}$} & \multirow{2}{*}{ Total } & \multirow{2}{*}{$\begin{array}{r}\text { Weight } \\
23.7 \%\end{array}$} & \multirow{2}{*}{$\begin{array}{c}\text { Risk Difference } \\
\text { M-H, Random, 95\% CI } \\
-0.33[-0.56,-0.11]\end{array}$} & \multicolumn{2}{|c|}{$\begin{array}{c}\text { Risk Difference } \\
\text { M-H, Random, 95\% CI }\end{array}$} \\
\hline & & & & & & & 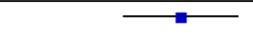 & \\
\hline Abdelhalim 2014 & 0 & 20 & 0 & 20 & $27.3 \%$ & $0.00[-0.09,0.09]$ & & \\
\hline Elhendawy 2016 & 9 & 44 & 6 & 44 & $25.8 \%$ & $0.07[-0.09,0.22]$ & & \\
\hline Ghobrial 2018 & 2 & 20 & 14 & 20 & $23.2 \%$ & $-0.60[-0.84,-0.36]$ & 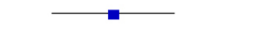 & \\
\hline Total $(95 \% \mathrm{Cl})$ & & 102 & & 102 & $100.0 \%$ & $-0.20[-0.48,0.07]$ & & \\
\hline Total events & 11 & & 26 & & & & & \\
\hline $\begin{array}{l}\text { Heterogeneity: } \mathrm{Tau}^{2}= \\
\text { Test for overall effect: }\end{array}$ & $\begin{array}{l}0.07 ; \mathrm{Chi}^{2} \\
\mathrm{Z}=1.43\end{array}$ & $\begin{array}{l}2=33 \\
(P=0\end{array}$ & $\begin{array}{l}.34, \mathrm{df}= \\
15)\end{array}$ & $3(P<$ & 00 & $I^{2}=91 \%$ & $\begin{array}{l}-0.5 \\
\text { Favours [APC] }\end{array}$ & $\begin{array}{ll} & 0 \\
\text { Favours [EB }\end{array}$ \\
\hline
\end{tabular}

Annex Figure 7. Adverse events.

Annex Table 1. Risk of bias (RoB-2) tool.

\begin{tabular}{|c|c|c|c|c|c|}
\hline \multicolumn{2}{|l|}{ Study } & Elhendawy & Ghobrial & Abdelhalim & $\begin{array}{l}\text { Abd Al- } \\
\text { Wahab }\end{array}$ \\
\hline \multirow{4}{*}{$\begin{array}{l}\text { DOMAIN } 1 \\
\text { RANDOMIZATION } \\
\text { PROCESS }\end{array}$} & 1.1 Was the allocation sequence random? & Y & Y & Y & Y \\
\hline & 1.2 Allocation sequence concealed? & Y & Y & PY & Y \\
\hline & $\begin{array}{l}\text { 1.3 Baseline imbalances suggest a problem with the rando- } \\
\text { mization process? }\end{array}$ & N & N & $\mathrm{N}$ & N \\
\hline & Risk of bias judgment & LOW & LOW & LOW & LOW \\
\hline \multirow{5}{*}{$\begin{array}{l}\text { DOMAIN } 2 \\
\text { DEVIATIONS } \\
\text { FROM INTENDED } \\
\text { INTERVENTIONS }\end{array}$} & 2.1. Participants aware of their assigned intervention? & PY & PY & PY & PY \\
\hline & $\begin{array}{l}\text { 2.2. Carers and people delivering the interventions aware of } \\
\text { participants' assigned intervention? }\end{array}$ & Y & Y & Y & Y \\
\hline & $\begin{array}{l}\text { 2.3. Were there deviations that arose because of the trial } \\
\text { context? }\end{array}$ & N & N & N & $\mathrm{N}$ \\
\hline & $\begin{array}{l}\text { 2.6 Appropriate analysis to estimate the effect of assign- } \\
\text { ment to intervention? }\end{array}$ & PY & PY & PY & PY \\
\hline & Risk-of-bias judgment & LOW & LOW & LOW & LOW \\
\hline \multirow{2}{*}{$\begin{array}{l}\text { DOMAIN } 3 \\
\text { MISSING OUTCOME DATA }\end{array}$} & $\begin{array}{c}\text { 3.1 Were data for this outcome available for all, or nearly all, } \\
\text { randomized participants? }\end{array}$ & PY & Y & PY & PY \\
\hline & Risk-of-bias judgment & LOW & LOW & LOW & LOW \\
\hline \multirow{5}{*}{$\begin{array}{l}\text { DOMAIN } 4 \\
\text { MEASUREMENT OF THE } \\
\text { OUTCOME }\end{array}$} & $\begin{array}{l}\text { 4.1 Was the method of measuring the outcome inappro- } \\
\text { priate? }\end{array}$ & N & N & N & N \\
\hline & $\begin{array}{l}\text { 4.2 Measurement or ascertainment of outcome differs } \\
\text { between groups? }\end{array}$ & N & N & N & $\mathrm{N}$ \\
\hline & $\begin{array}{l}\text { 4.3 Outcome assessors aware of the intervention received } \\
\text { by participants? }\end{array}$ & Y & Y & Y & Y \\
\hline & $\begin{array}{l}\text { 4.4 Could assessment of the outcome have been influenced } \\
\text { by knowledge of intervention received? }\end{array}$ & PN & PN & PN & PN \\
\hline & Risk-of-bias judgment & LOW & LOW & LOW & LOW \\
\hline \multirow{4}{*}{$\begin{array}{l}\text { DOMAIN } 5 \\
\text { SELECTION OF THE } \\
\text { REPORTED RESULT }\end{array}$} & $\begin{array}{l}\text { 5.1 Trial analyzed in accordance with a prespecified analysis } \\
\text { plan? }\end{array}$ & PY & PY & PY & PY \\
\hline & $\begin{array}{l}5.2 \text { Is the result selected from multiple eligible outcome } \\
\text { measurements? }\end{array}$ & PN & PN & PN & PN \\
\hline & $\begin{array}{l}5.3 \text { Is the result selected from multiple eligible analyses of } \\
\text { the data? }\end{array}$ & PN & PN & PN & PN \\
\hline & Risk-of-bias judgment & LOW & LOW & LOW & LOW \\
\hline \multicolumn{2}{|l|}{$\begin{array}{l}\text { OVERALL } \\
\text { RISK OF BIAS }\end{array}$} & LOW & LOW & LOW & LOW \\
\hline
\end{tabular}

Y: yes; PY: probably yes; N: no; PN: probably no. 


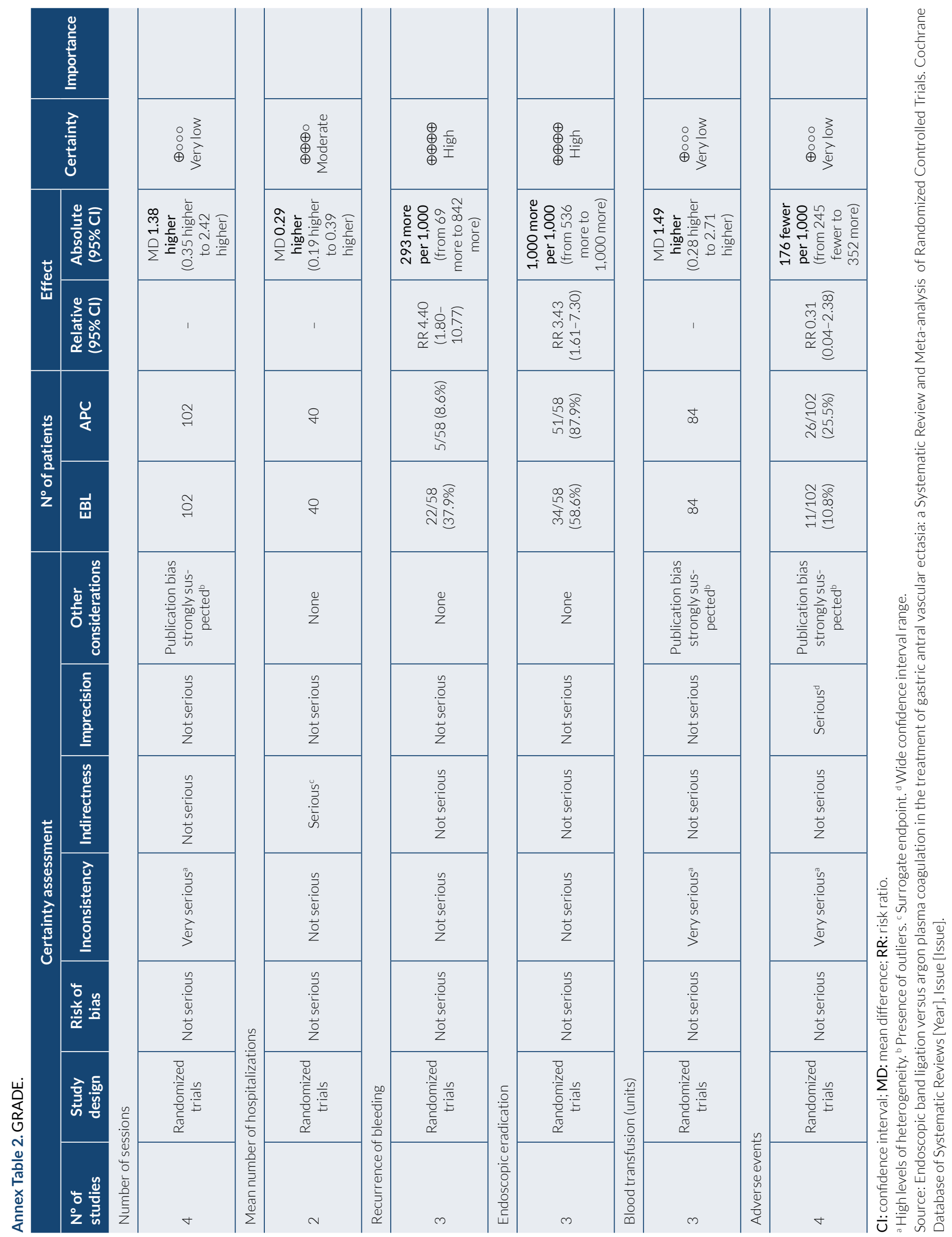

